Artigo

\title{
O empresário, a ONG, os marisqueiros, a criança: um estudo de caso sobre a variação de sentidos de um manguezal em disputa
}

\author{
Cecília Campello do Amaral Mello ${ }^{1}$ \\ Universidade Federal do Rio de Janeiro, Rio de Janeiro, RJ, Brasil \\ ceciliamellobr@gmail.com
}

RESUMO: O presente artigo propõe-se a apresentar algumas inflexões teórico-metodológicas nascidas da etnografia de um processo de conflito ambiental em uma área de manguezal ocupada por grupos extrativistas no Nordeste brasileiro. Pretende-se apresentar como os diferentes actantes em disputa - quais sejam, os empresários, os pesquisadores associados às ONGs ambientalistas, os marisqueiros e as crianças de um movimento cultural afroindigena - nomeiam, definem e se apropriam daquilo que designam, cada um a seu modo, faz̧enda de camarão, ecossistema manguezal ou, simplesmente, mangue. A partir de uma pesquisa de campo de longa duração, este artigo propõe o exercício analítico de se aproximar dos percursos e deslocamentos nativos nas situações em que acontecem, tornando possível o vislumbre de múltiplos modos de ser extrativista e indicando, em consequência, a necessidade de uma complexificação da noção de grupo ou população extrativista.

PALAVRAS-CHAVE: etnografia, reserva extrativista, conflito ambiental, território, Cassurubá, Bahia. 


\section{Introdução}

Este artigo apresenta algumas consequências teórico-metodológicas oriundas do material etnográfico sobre um caso de conflito ambiental envolvendo disputas em torno dos sentidos, usos e modos de apropriação dos manguezais situados entre os municípios de Caravelas e Nova Viçosa, no extremo sul do estado da Bahia. Fruto de uma pesquisa de campo de longa duração ${ }^{2}$, este artigo propõe o exercício de se buscar novas formas de inteligibilidade para a relação dos grupos sociais com o espaço em que vivem - aquele que a Ecologia designaria meio ambiente, uma Economia heterodoxa chamaria de áreas de uso comum (Ostrom, 1990), o agenciamento Estado-empresa nomearia como terras devolutas e as pessoas aqui concernidas, simplesmente de mangue ${ }^{3}$.

Essa foi a última etapa de uma pesquisa de campo em nível de doutorado que teve como ponto de partida uma antropologia da política em sua dimensão eleitoral. A etnografia completa, da qual este artigo é parte, descreve o que poderia chamar-se de um processo de capilarização da política: inicia-se nas eleições - modo macroscópio da política, com tempo, espaço e sujeitos passíveis de algum modo de circunscrição - e encerra-se no manguezal, meio transbordante e mutável, acessado por actantes cujas identidades não são facilmente delimitáveis.

O encontro desta etnógrafa com o manguezal engendrou a necessidade de se rastrear o traçado das múltiplas formas de deslocamento dos grupos sociais ditos extrativistas, categoria que, para ser fiel à empiria, precisa incluir, como veremos, não apenas pescadores e marisqueiros, mas também outros actantes que de alguma maneira se relacionam com o manguezal. O exercício aqui proposto aponta para a necessidade de, por um lado, escapar daquelas estratégias que procuram estratificar este meio, tomando-o como algo já dado, e, por outro lado, fugir do seu correlato no plano que poderíamos chamar de identitário, a saber, a sedentarização da figura do extrativista, que, vista de perto, desloca-se e desdobra-se em muitos(as): o pescador, a marisqueira, o morador, o afro-indígena ${ }^{4}$, a criança.

Como apreender seus múltiplos deslocamentos no meio em que vivem, irredutíveis à concepção comumente acionada por nós, antropólogos, de território enquanto base natural sobre a qual se erigiriam representações sociais? Como escapar do que poderíamos descrever como um dos últimos refúgios do naturalismo na Antropologia e ser fiel ao estudo propriamente etnográfico dos caminhos traçados e dos acontecimentos que organizam o modo de vida dos chamados grupos extrativistas? Como construir outra cartografia, não fundada 
no primado naturalizante do território biofísico, ou mesmo numa concepção estratigráfica (Geertz, 1989) de território enquanto uma base natural à qual se somariam dimensões ou planos culturais ou sociais?

Proponho um olhar para o território como algo que não está dado previamente, "suspendendo-o" em princípio da análise, seguindo aquilo que denominou-se exercício de minoração (Deleuze, 2010). Trata-se de um procedimento ou um tratamento em relação ao material que busca "suspender", extrair ou extirpar os elementos de poder (tais como a História, o Território, a Estrutura, os Padrões, as Constantes) que possam vir a bloquear a capacidade de se perceber os devires e as potencialidades pouco exploradas trazidos pela etnografia ${ }^{5}$.

Com esse exercício não ensejo de modo algum questionar a pertinência política das categorias extrativista e território, que têm se revelado centrais na reivindicações dos mais diversos direitos dos quais esses grupos são legítimos portadores. Ao contrário, pretende-se, com a presente reflexão, trazer à tona modos não óbvios de ser extrativista e demonstrar como a sustentação de um olhar atento aos caminhos idiossincráticos desenhados por essas pessoas em relação com seu meio tem por efeito a ampliação do que poderia ou deveria ser entendido enquanto seu território. Antes de se falar em território, é preciso estar atento aos caminhos que o constituem. A proposta deste artigo é tão-somente a de verificar as consequências etnográficas desta assertiva.

\section{Os descaminhos rumo ao desenvolvimento}

Desaparecem as margens nas quais os mais pobres e mais móveis haviam conseguido subsistir, aproveitando tolerâncias, negligências, regras esquecidas ou fatos incontestados.

(Foucault, 1994: 467)

Para compreender os percursos traçados pelos grupos sociais extrativistas em sua relação com o manguezal, é preciso, primeiramente, contextualizar os acontecimentos de diferentes ordens que ocorreram na região a partir do ano de 2003. Em janeiro daquele ano, uma grande mortandade de caranguejos-uçá, por causas desconhecidas, atingiu a região de Canavieiras, situada 340 quilômetros ao norte de Caravelas. Com isso, grupos de extrativistas daquela localidade deslocaram-se à Caravelas à procura do crustáceo praticamente extinto em sua região. A chegada de grupos de marisqueiros causou forte tensão em Caravelas: pescadores 
e marisqueiros caravelenses indignaram-se com o grande volume capturado de uma só vez, com as técnicas predatórias utilizadas e, acima de tudo, com o que foi considerado uma invasão dos seus territórios de uso tradicional por um grupo entendido como de fora.

Este evento engendrou forte oposição dos marisqueiros de Caravelas ao escritório do Ibama local, que não teria tomado medidas repressivas para impedir a extração do crustáceo pelos marisqueiros do município ao norte. O conflito em torno do acesso aos recursos do manguezal provocou manifestações de pescadores e marisqueiros de Caravelas, que passaram a reivindicar dos poderes públicos uma proteção jurídica para o território de onde obtêm sua subsistência. Somado a esse fato, os danos sociais e ecológicos associados à iminente instalação de uma grande fazenda de camarão nos manguezais da região engendraram um processo de luta sem precedentes, protagonizado por pescadores e marisqueiros de Caravelas, com apoio de ONGs ambientalistas e pesquisadores, que culminou na implementação da Reserva Extrativista do Cassurubá, instituída em junho de 2009, abrangendo a maior parte dos manguezais da região.

Em 2004, a doença que provocou a grande mortandade de caranguejos em Canavieiras alastrou-se para o sul do estado e atingiu os manguezais de Caravelas, reduzindo drasticamente a quantidade de caranguejos (Schmidt, 2006), principal recurso extraído pelos marisqueiros, garantidor de sua subsistência. Este desastre ecológico - imprevisto, inédito e responsável pelo desaparecimento do caranguejo em toda a extensão dos manguezais da região - pôs em movimento grande quantidade de famílias da região ribeirinha. O assim chamado "processo de urbanização" dos moradores da zona ribeirinha - que já vinha ocorrendo de forma intermitente há anos - intensificou-se sobremaneira à época do sumiço do caranguejo. Famílias provenientes dos sítios na região ribeirinha mudaram-se para a sede do município de Caravelas, onde ocuparam uma área de manguezal contígua ao centro da cidade, à beira do rio dos Macacos. Esta área, sujeita a constantes alagamentos por estar sob influência das marés, foi loteada, legalizada e doada pelo então prefeito aos moradores da zona ribeirinha, numa jogada eleitoral que garantiu a eleição de seu sucessor e aliado político. Parcela considerável da população hoje residente no chamado Bairro Novo é proveniente dos sítios ou das ilhas ao longo do estuário do rio Caravelas e de seus afluentes.

Em outubro de 2005, após meses de intensos rumores, confirmou-se a notícia de que uma grande fazenda de carcinicultura estava em processo de licenciamento no órgão ambiental estadual da Bahia. O projeto previsto seria a maior fazenda de camarão instalada no Brasil - com 1.500 hectares -, sobre o manguezal da cidade de Caravelas, entre os rios 
dos Macacos e Massangano, um empreendimento controverso que propalava a criação de milhares de vagas, gerando um misto de fascínio e suspeita nos moradores que, ao mesmo tempo, desejavam o desenvolvimento e temiam seus efeitos potencialmente danosos para a parcela significativa da população que vive do extrativismo de crustáceos e da pesca ${ }^{6}$.

Embora o projeto já existisse nos limbos da burocracia estadual desde 2002, os moradores da cidade nada sabiam a seu respeito. A grande fazenda, do ponto de vista dos moradores, surgiu de um dia para o outro em seu horizonte, de maneira terrivelmente presente e influente. Talvez muito da força com que se impôs provenha justamente do fato de não ter uma história conhecida que pudesse ser contada, isto é, ao projetar-se para fora da história, o empreendimento instituiu-se como um fato, um dado, um estado de coisas inelutável, quase natural ou até mesmo sobrenatural: o empreendimento não existia nem precisou existir e, no entanto, produziu efeitos sociais muito concretos na vida dos caravelenses.

Rumores de que Caravelas, município com em torno de 20 mil habitantes, fora escolhida pelo órgão de desenvolvimento da pesca do governo do estado da Bahia como local com vocação natural para a implantação de fazendas de camarão começaram a ecoar no ano de 2004. Para alguns moradores, Caravelas parecia estar em vias de retomar seu caminho rumo ao desenvolvimento, sinônimo, neste caso, de superação de uma situação de estagnação econômica por meio da chamada geração de empregos e consequente aumento da renda na cidade.

Caravelas é descrita por seus moradores mais velhos como a cidade do já teve, uma alusão aos vários ciclos econômicos que ali se sucederam e se exauriram. De grande produtor de óleo de baleia, utilizado como argamassa de construções no Brasil Colônia, a importante centro do comércio regional na primeira metade do século xx, Caravelas teve sua história marcada pela construção da ferrovia Bahia-Minas, inaugurada em 1881 e extinta em 1966, que ligava o distrito de Ponta de Areia $^{7}$ à Araçuaí, no norte mineiro. O município foi um polo de expansão da indústria madeireira, hoje extinta, assim como da produção cafeeira e agropecuária na Bahia, atualmente pouco significativas. As prospecções por petróleo na década de 1980 não redundaram em exploração do recurso e o turismo para a região dos Abrolhos, arquipélago que tornou-se Parque Nacional Marinho ${ }^{8}$, localizado a 72 quilômetros de distância do litoral, é intermitente e acessível apenas para pesquisadores ou para uma elite de aficionados pela prática do mergulho submarino.

A partir do final da década de 1980, a monocultura do eucalipto expandiu-se rapidamente pela região, ocupando amplas faixas de terra até então destinadas à agricultura familiar ou à pecuária extensiva. A expansão do eucalipto provocou o êxodo da população de antigas áreas rurais 
produtoras de alimentos para centros urbanos regionais, como Teixeira de Freitas, ou para capitais, como Belo Horizonte ou Vitória, a 90, 750 e 400 quilômetros de distância, respectivamente9 . Nesse contexto de reduzidas possibilidades de inserção econômica no mercado regional ou nacional, a produção de camarão em cativeiro, também conhecida como carcinicultura ${ }^{10}$, impôsse aos moradores da cidade como uma solução para o quadro de estagnação econômica da região e como eixo em torno do qual se daria o tão desejado desenvolvimento ${ }^{11}$.

A iminente chegada do empreendimento desencadeou uma intensa mobilização política na cidade ${ }^{12}$. Delineava-se uma acirrada disputa acerca dos múltiplos sentidos das áreas de uso comum (Ostrom, 1990) do município. Os dados etnográficos revelam que os actantes (Latour, 2005) concernidos possuíam concepções distintas sobre o acesso, os usos e os modos de relação com o manguezal. Para demonstrar isso, apresento a seguir três perspectivas distintas, a saber, a do empreendedor, a dos pesquisadores associados às ONGs e a dos pescadores e marisqueiros, que dão contornos a três possíveis manguezais ${ }^{13}$. Tal meio era para os primeiros uma fazenda em potencial, para os segundos, um ecossistema e, para os pescadores e os marisqueiros, o mangue, simplesmente ${ }^{14}$.

O material por meio do qual é possível conhecer o manguezal do empreendedor é o Estudo de Impacto Ambiental e o Relatório de Impacto no Meio Ambiente (EIA-RIMA) desse projeto de carcinicultura, bem como um texto exemplar, publicado pela Revista da Associação Brasileira de Criadores de Camarão. O Parecer Técnico Independente ao EIA-RIMA é, por sua vez, a fonte que permitiu o acesso ao manguezal tal qual concebido pelos pesquisadores associados às ONGs ambientalistas. Finalmente, tive acesso ao manguezal dos pescadores, dos marisqueiros e das crianças do movimento cultural afro-indigena de forma direta, diária e intensa durante a última etapa de minha pesquisa de campo no município.

\section{Manguezal como fazenda em potencial}

O manguezal do empreendedor é concebido como pura negatividade. Aí se define a atividade da mariscagem enquanto um fardo insalubre atribuído a seres desumanizados, que não teriam outra escolha a não ser submeter-se a um trabalho abjeto. Segundo o autor de um texto que revela a visão dos carcinicultores sobre o manguezal, trata-se de uma:

(...) condenação inumana viver e sobreviver para sempre nos inóspitos manguezais (...) sob a sentença de pena perpétua de se nascer na lama e em 
CECílIA CAMPELLO do AMARAL MELLO. O EMPRESÁRIO, A ONG, OS MARISQUEIROS, A CRIANÇA...

lama transformar-se. (...) A insalubre atividade dos catadores de caranguejos é tão sub-humana quanto aquela dos catadores de lixo (Guimarães, 2005: 19).

O manguezal é definido como um ecossistema pútrido, fétido e infeccioso, terra podre da qual não é possível extrair uma vida digna. Os marisqueiros são representados enquanto seres em que a própria humanidade está em causa, habitantes de uma zona liminar, que tangenciaria o mundo dos animais: como seres anfíbios, viveriam "entre as águas do rio e a lama dos mangues", sem “acesso à saúde, à educação, a qualquer coisa da terra dos humanos”. Seus corpos e gestos assemelham-se àqueles dos caranguejos:

Eles se assemelhavam aos caranguejos que catavam quando se agachavam e enlameavam o corpo todo; arrastavam-se no chão lodoso em fermentação pela urina, fezes e lixo (Guimarães, 2005: 20).

Na cosmologia dos empresários do camarão em cativeiro, o trabalho nas fazendas seria o expediente redentor, a atividade por excelência capaz de libertar esses seres anfibios dos grilhões de uma condição sub-humana ou pré-animal, bem como de transformar um ambiente poluto num ambiente higienizado. De um lado, o trabalho e o desenvolvimento representados pelas fazendas liberariam o manguezal de sua poluição moral natural e, de outro, os marisqueiros seriam alçados à humanidade propriamente dita ao tornarem-se trabalhadores. Nas palavras do mesmo autor:

(...) a atividade [do cultivo de camarões] consolidou-se e em consequência vieram os empregos, as divisas, o desenvolvimento das indústrias afins, o incremento do comércio local e, finalmente, a oportunidade de os homenscaranguejos saírem da fossa pantanosa e se encantarem em homem-homem (Guimarães, 2005: 20).

Ainda segundo a visão empresarial, os ambientalistas ("homens-homens de terra firme”) são apresentados como sujeitos românticos e responsáveis pela despossessão dos marisqueiros. Sua oposição à carcinicultura seria um fator de impedimento do desenvolvimento econômico e, por conseguinte, da redenção moral dos extrativistas. Afirma Guimarães:

Os homens-homens de terra firme não lhes permitem sair [do mangue]. Não querem que tenham acesso à saúde, à educação, à carteira de trabalho assinada. Pelo contrário: tramam matar a atividade que os libertaria. Discursam que ela acabará com seus caranguejos, que exterminará os manguezais, que assassinará os rios. Mentira. Eles apenas acham poético catar caranguejo para sobreviver (Guimarães, 2005: 20) 
CECÍlIA CAMPELLO dO AMARAL MELLO. O EMPRESÁRIO, A ONG, OS MARISQUEIROS, A CRIANÇA...

Interessante perceber a notável e incômoda semelhança entre este texto e o livro Homens e Caranguejos, de Josué de Castro, misto de romance e autobiografia, nascido nos alagados da cidade do Recife. São, a meu ver, significativas as convergências semânticas entre o livro deste homem de esquerda e o texto do ideólogo dos empresários proprietários de fazendas de camarão. Castro definiu os moradores dos manguezais como "seres anfíbios - habitantes da terra e da água, meio homens e meio bichos” (1967: 12) e é provavelmente daí que o defensor dos fazendeiros de camarão retira a expressão. Castro enfatiza, ao longo do livro, a grande semelhança entre os habitantes do mangue e os caranguejos:

Alimentados na infância com o caldo do caranguejo: este leite da lama. Seres humanos que se faziam assim irmãos de leite dos caranguejos. Que aprendiam a engatinhar e a andar com os caranguejos da lama e que depois de terem bebido na infância este leite de lama, de se terem enlambuzado com o caldo grosso da lama dos mangues, de se terem impregnado do seu cheiro de terra podre e maresia, nunca mais se podiam libertar desta crosta de lama que os tornava tão parecidos com os caranguejos, seus irmãos, com as suas duras carapaças também enlambuzadas de lama (Castro, 1967: 12-13).

Como explicar esta perturbadora semelhança entre o discurso empresarial e o texto de um homem de esquerda? Em primeiro lugar, é importante ponderar que Castro referiase aos manguezais urbanos de Recife, em franca deterioração, onde se amontoavam moradores oriundos do êxodo das áreas rurais, ou seja, não se tratava de modo algum de áreas afluentes e impolutas como aquelas verificadas em Caravelas. Mas isso não obscurece o fato de que ambos - empresários e homens de esquerda - possam recair neste nosso “adversário sempre vivaz”, “obstáculo permanente”, expediente que "mediatiza todo olhar sobre as diferenças para identificá-las e finalmente aboli-las" (Clastres, 1978: 1314): o etnocentrismo. Não falo aqui daquele etnocentrismo compartilhado por todas as culturas, que considera bárbaro o que não se pratica em sua terra, tendência universal em considerar o seu modo de vida o mais "correto" e o mais "natural" (Lévi-Strauss, 1980). Refiro-me a um determinado etnocentrismo - o etnocentrismo ocidental - que, ao definir o outro por aquilo que ele não é, abolindo as diferenças em nome de uma identidade, acaba por funcionar como um dispositivo de conversão de pessoas e meios ambientes em mão de obra e recursos naturais.

Este seria um exemplo de que empresários e homens de esquerda podem vir a situar-se na faixa comum de um repertório político desenvolvimentista predatório que, 
CECílIA CAMPELLO do AMARAL MELLO. O EMPRESÁRIO, A ONG, OS MARISQUEIROS, A CRIANÇA...

etnocentricamente, define extrativistas - sejam pescadores, marisqueiros, quilombolas ou indígenas - como "entraves" ao desenvolvimento (no singular: desejo universal e rumo inexorável $)^{15}$.

Porém, ater-se tão-somente aos chamados empreendedores como unidade de análise seria negligenciar o fato de que, ao contrário do que postula a axiomática liberal, o empresário ou o setor privado nunca age sozinho: o Estado revela-se, neste caso, o grande fomentador da expansão dos negócios privados sobre terras de uso comum. É mais acurado, portanto, a menção não apenas ao empreendedor, mas também ao agenciamento Estado-empresa. No evento estudado, esse vínculo explicita-se e materializa-se em um grande inventário intitulado Macrodiagnóstico do potencial da Babia para carcinicultura marinha, produzido em 2003 pela Bahia Pesca, empresa de desenvolvimento da atividade pesqueira no estado, ligada à Secretaria de Agricultura do Estado da Bahia.

Por meio de mapeamentos, planilhas e imagens de satélite, a Bahia Pesca desenhou um zoneamento econômico circunscrevendo os manguezais - apresentados como terras vazias - e, desse modo, liberou territórios não explorados (as chamadas “terras devolutas") para o investimento de capital, expandindo a fronteira da acumulação para áreas de uso comum, em que predominam atividades extrativistas, como a pesca e a mariscagem ${ }^{16} . \mathrm{Na}$ esteira desse mapeamento, uma série de municípios da zona costeira da Bahia foi escolhida para a instalação de fazendas, com as consequências que veremos a seguir.

\section{O ecossistema manguezal ${ }^{17}$}

E o que seria o manguezal do ponto de vista dos pesquisadores associados às universidades e ONGs ambientalistas que atuam na região? Em sua quase totalidade, são biólogos e oceanógrafos, pessoas treinadas para um tipo específico de prática científica, indissociável da pesquisa de campo, isto é, de um olhar atento aos processos ecológicos que se desdobram em um mundo complexo, dos quais se busca extrair alguma inteligibilidade, sem necessariamente o imperativo de se chegar a "definições gerais que transcendam as situações" (Stengers, 1997: 69) ${ }^{18}$.

A área que a empresa de camarão desejava suprimir é vista como parte de um ecossistema, regulado por uma dinâmica natural própria, habitado por determinadas populações e protegido por legislações específicas. O esforço de análise dos pesquisadores atuantes na região dá-se no sentido da construção de uma sensibilidade própria, que permita vislumbrar as conexões 
específicas que se dão em uma rede de entes heterogêneos - rios, mangues, oceano, recifes de corais, espécies de peixe e pescadores -, produzindo efeitos práticos passíveis de serem apreendidos cientificamente. Tais estudiosos apontam uma série de relações ecológicas entre o rio Caravelas, seus afluentes e manguezais e os recifes de corais do Banco dos Abrolhos e espécies que aí se encontram. Em poucas palavras, os estudos destacam a importância biológica do manguezal, ecossistema em que se reproduz parte considerável da fauna marinha - daí sua denominação poética enquanto "o berçário do mar" - que, em idade adulta, ganha os mares e ambientes recifais, sustentando a atividade pesqueira na região, não por acaso a mais produtiva do Nordeste. Cito-os:

A importância dos manguezais, que transcende as suas próprias fronteiras, vem sendo crescentemente reconhecida, a partir da constatação inicial de que a produção pesqueira dos estuários está diretamente relacionada com a produção de folhas dos mangues (MMA, 1996). Mais recentemente, a partir do acúmulo de evidências adquiridas em sistemas recifais nas adjacências de manguezais, Mumby et al. (2004) demonstraram, de forma conclusiva, a estreita relação entre a produtividade pesqueira em ambientes recifais e a presença de manguezais em boas condições de conservação. Não é por acaso que a produção pesqueira do Banco dos Abrolhos é significativamente maior do que a de outras áreas do Nordeste brasileiro (Moura et al., 2005: 15).

A produção de camarão em cativeiro, ou carcinicultura, é entendida como uma das práticas que vêm ameaçando a integridade dos manguezais - e com eles dos estoques pesqueiros - no Brasil e no mundo. Embora a carcinicultura necessite de recursos hídricos livres de poluição e, de fato, seja economicamente viável na medida em que ganha do poder público outorgas para ter acesso livre e gratuito às águas que banham os manguezais, paradoxalmente, por lançar efluentes contendo compostos químicos tóxicos sem tratamento de volta ao ecossistema, acaba por contaminar o estuário, contribuindo para o esgotamento dos recursos e provocando o alastramento de doenças no próprio camarão. Trata-se, portanto, de uma atividade que, como nenhuma outra, revela-se insustentável do ponto de vista ecológico e também econômico.

Nos países em que instalou-se esse tipo de atividade, um rastro de destruição em larga escala foi amplamente registrado ${ }^{19}$ em função da desestabilização de ecossistemas e modos de vida, ocasionando não o esperado desenvolvimento e a prosperidade, mas a geração de fome e miséria para os habitantes de zonas costeiras outrora afluentes. Ainda segundo os autores: 
(...) os manguezais vêm sendo crescentemente impactados pela expansão urbana e industrial, bem como pela implantação indiscriminada de enormes fazendas de cultivo de camarões (e.g. Batista e Tupinambá, 2004; Leroy e Silvestre, 2004; GT Carcinicultura, 2005). O projeto da Coopex propõe extensas áreas de aterros e drenagens (...), além de transformar o canal estuarino na área final de despejo dos resíduos da fazenda (rações, nitratos, uréia, fosfato e calcários, entre outros). Como demonstra a literatura científica (e.g. Coelho Júnior e Schaeffer-Novelli, 2000), tais atividades ocasionarão intensa desestruturação da funcionalidade do ecossistema, comprometendo a sobrevivência das espécies animais e vegetais e interferindo de forma significativa nos processos de reprodução da fauna, desencadeando reflexos em cadeia na fauna marinha como um todo (MMA, 1996) (Moura et al., 2005: 16).

Segundo os pesquisadores, tal atividade produziria o que, numa linguagem emprestada à economia neoclássica, denominou-se "externalidades negativas", isto é, custos sociais que, não sendo contabilizados pelo mercado, dariam origem a distorções no valor de uma mercadoria:

Quando as externalidades se encontram presentes, o preço de uma mercadoria - o camarão, neste caso - não reflete necessariamente seu valor social. As externalidades produzidas pela carcinicultura são aquelas denominadas de negativas, pois a ação de despejo de efluentes nos rios impõe custos sobre as outras partes: as comunidades, os governos e a sociedade como um todo (Moura et al., 2005: 23).

Para outro conjunto de pesquisadores que também assina o parecer, mas cuja perspectiva é mais próxima daquela da justiça ambiental ${ }^{20}$, essas “distorções” não seriam desvios ou erros de funcionamento do mercado, mas processos a ele imanentes, que apontam uma dimensão que a economia, por si só, não explica, a saber, os mecanismos propriamente políticos que tornam esta e outras atividades economicamente viáveis. Se um mecanismo de ordem regulatória obrigasse o empresário a internalizar os custos sociais e ambientais da carcinicultura no preço do camarão, a atividade tornaria-se pouco atraente do ponto de vista financeiro e tenderia a desaparecer. Segundo esses pesquisadores ${ }^{21}$, o camarão das fazendas é barato porque seus custos de produção são pagos por uma parcela "vulnerabilizada" da sociedade, devido à vigência de um mecanismo de dominação sociopolítico que permite que alguns (pescadores) recebam maior carga dos danos ambientais que outros (empresários). A assimetria de poder entre esses actantes - e não uma mera distorção de mercado - seria, portanto, condição para que práticas predatórias do ponto de vista ambiental sejam instituídas e expandidas. 
CECÍlIA CAMPELLO dO AMARAL MELLO. O EMPRESÁRIO, A ONG, OS MARISQUEIROS, A CRIANÇA...

Entre 2001 e 2006, as fazendas de camarão começaram a instalar-se na zona costeira dos municípios baianos (como Salinas de Margarida, Santo Amaro, Valença, Jandaíra e Canavieiras), sendo licenciadas à revelia da normativa ambiental e sem a realização de audiências públicas previstas em lei. Estudos identificaram inúmeros danos ambientais (desmatamentos, assoreamentos, drenagem e contaminação) das áreas de manguezal até então acessadas por pescadores e marisqueiros desses municípios que, além de tudo, tiveram seu acesso ao mar impedido devido à construção de tanques e cercas, que passaram a obstruir os caminhos tradicionais (Rede Manguemar, 2007). Em alguns dos municípios, os pescadores rebelaram-se contra a instalação das fazendas em seus territórios de uso comum e sofreram uma série de violências e violações de direitos humanos, registrada por diversos estudos ${ }^{22}$.

Além de ser regulado por uma ordem natural, o manguezal também é objeto de inúmeras regulamentações jurídicas que visam garantir sua vigência. Área considerada pelo governo brasileiro de extrema importância biológica, localiza-se no limite da Zona de Amortecimento do Parque Nacional Marinho dos Abrolhos e dentro do que era área em estudo para a criação de uma Unidade de Conservação. Trata-se de um território atravessado por uma série de dispositivos jurídico-políticos previstos na legislação ambiental.

O manguezal dos pesquisadores associados às ongs é, portanto, um híbrido (Latour, 1994) político-jurídico-ecológico, a meio caminho entre a afluência e a escassez: um ecossistema dinâmico, reprodutor de recursos, que pode ser irreversivelmente desestabilizado. De máquina de produção de vida e base econômica dos moradores da região, o manguezal pode converter-se num ambiente frágil, desestabilizado e finito a partir da introdução de práticas entendidas como predatórias em seus domínios. Tais práticas predatórias não se restringem ao que os pesquisadores entendem como sendo o ecossistema manguezal, mas se impõem também às comunidades pesqueiras, que enfrentam situações de violência ${ }^{23}$ no processo de apropriação privada de seus territórios de uso comum.

\section{O mangue dos pescadores e marisqueiros}

Descrever o manguezal dos pescadores e marisqueiros é descrever menos um lugar que uma relação entre diversos modos de ser extrativista e o mangue. Ao longo dos 20 meses em que vivi em Caravelas, morando junto a uma família que compõe o movimento cultural afro-indigena e pesquisando sua produção artística e política, estive em contato permanente 
com as crianças e com os integrantes do Bloco de Índio e das Nagôs ${ }^{24}$, que também são pescadores e marisqueiros. Com eles, pude observar sete formas de relação com o manguezal - certamente há muitas mais - até então desconhecidas para mim.

A chamada "divisão rural-urbana" no município não pode ser entendida como uma fronteira pura e simples, definida por uma lógica binária fixa ou linear. Se há fronteira, esta se move segundo um princípio polimorfo, contrátil e fluido (Browder e Godfrey, 1997), acompanhando os movimentos de desterritorialização e reterritorialização ${ }^{25}$ dos grupos extrativistas. É no traçado produzido pela repetição do movimento dos muitos modos-deser-extrativista que um determinado meio é formado. Se esquecermos ou "suspendermos" o território (o fundo) e olharmos apenas para os extrativistas (a figura), o que se observa são linhas, traços, caminhos, conforme evidenciado no material etnográfico apresentado a seguir.

A prática extrativista, isto é, a extração e coleta de mariscos, crustáceos e outros recursos disponíveis no ambiente, é denominada pelos nativos de giro. O mangue é o lugar em que se faz ou do qual se tira o giro e que corresponde às extremidades das ilhas, que são propriamente ilhas fluviais ou regiões do continente entrecortadas por rios e de difícil acesso por terra. A roşa é a pequena lavoura que os moradores da região ribeirinha costumam cultivar (mandioca, abacaxi, coco ou dendê), associada à criação de pequenos animais. Ela se localiza entre a casa e o manguezal propriamente dito. Mas roça também é o nome que se dá em geral ao bloco casa-roça-mangue: um termo empregado em frases como "este final de semana eu vou pra roça”, ou seja, para as terras localizadas rio acima. Diz-se também: "tô indo pra ilha" - ou "ele tá pra Tapera”, denominação de uma das ilhas. A casa corresponde ao núcleo das ilhas e são comuns agrupamentos familiares de duas a seis ou mais casas, com suas respectivas roças. O manguezal é tido como área de uso comum (Ostrom, 1990) e o acesso aos seus recursos é regulado por relações de parentesco, compadrio e amizade compartilhadas entre os chamados extrativistas.

A primeira forma de relação com o manguezal é a de pessoas que tiram seu giro do mangue e cujas casas localizam-se num meio anexo a ele, na ilha ou na roça. Esta é a figura considerada pelos órgãos ambientais como sendo o extrativista "por excelência", aquele que mora numa área contígua ao local do qual retira sua subsistência, vende seus mariscos para intermediários e frequenta a cidade raramente ou nos dias de feira. Trata-se do extrativista identificado nos estudos e laudos socioeconômicos que subsidiaram a criação de uma Unidade de Conservação Federal - a Reserva Extrativista do Cassurubá - na região ${ }^{26}$. É a pessoa certa no lugar certo: sobre ele não pairam quaisquer dúvidas quanto à sua identidade. 
O trabalho de campo, porém, vem mostrar que, embora evidentemente válido, este é apenas um dos múltiplos modos de ser extrativista. Tal condição de "extrativista por excelência" desdobra-se em muitos outros modos-de-ser, em função de determinados acontecimentos com os quais os pescadores e marisqueiros vêm se defrontando ao longo do tempo.

A segunda forma de relação com o manguezal pode ser entendida como um movimento de desterritorialização da primeira. Conforme dito, em 2003 houve uma grande e inédita mortandade de caranguejo em toda zona costeira baiana, o que gerou um grande afluxo de moradores da área ribeirinha de Caravelas para a cidade, em busca de algum tipo de renda alternativa ao extrativismo. Isso se traduziu, em muitos casos, numa inserção no mercado de trabalho informal: trabalho doméstico para as mulheres e construção civil para os homens.

Jane e sua cunhada Rita moraram muitos anos na roça, como designam a terra que a família de Manuel de Adeu ocupa entre o rio Caribê e o rio do Poço, na parte conhecida como Tapera. A Tapera é uma ilha relativamente próxima à cidade e à feira: se a maré estiver grande, isto é, enchendo, o percurso entre a ilha e a cidade leva 40 minutos de canoa, enquanto que, com a maré vazante, leva-se apenas 20 minutos no remo. Sua família é formada ao todo por treze irmãos que, sem exceção, vivem da extração de mariscos do manguezal. As casas de pau-a-pique eram o pouso certo após o trabalho entre quatro e dez da manhã catando mariscos e pescando. Em 2003, porém, o caranguejo começou a escassear, até sumir por completo. Durante o período da mortandade de caranguejo, Jane deixou de obter uma renda de aproximadamente 600 reais por mês. Ela tirava 150 reais por semana vendendo o catado do caranguejo para atravessadores. Isso a fez desfazer (literalmente desmontar) a casa de sua família na área ribeirinha. Seu marido Genilson levou as telhas da casa para a cidade e a reconstruiu no chamado Bairro Novo, ocupação recente de uma área de manguezal onde, antes, o traçado urbano terminava. Jane tornou-se, então, empregada doméstica na casa de uma família abastada e passou a ganhar meio salário mínimo por mês de trabalho, o equivalente ao que tirava do mangue a cada semana.

Essa mudança para a cidade não é entendida por Jane nem por seu marido como definitiva; eles sonham com juntar dinheiro para comprar as telhas que lhes permitiria refazer sua casa na ilha da Tapera. Quando concluí a pesquisa, Jane vivia numa casa de alvenaria no Bairro Novo, numa área sem água encanada ou saneamento básico (tal como na Tapera), porém, diferentemente de seu local de origem, sujeita a alagamentos constantes e doenças. Seu filho mais novo, então com 8 anos, contraiu hepatite B em meados de 2005 e a fez ter 
muitos gastos com medicamentos e exames. O marido de Jane, conhecido como pajé pelos moradores da região ribeirinha, também deixou de catar caranguejo e foi trabalhar como pedreiro na Barra, distrito à beira-mar que concentra as novas construções na cidade. Nos últimos meses de 2005, com o reaparecimento do caranguejo e da ostra, Jane e seu marido largaram esses empregos e voltaram ao giro no manguezal. Quando querem ficar mais perto dos recursos, voltam para a roça e se alojam temporariamente na casa dos parentes que ali permaneceram. Esta é uma segunda modalidade de relação com o manguezal: pode-se viver na cidade e fazer o seu giro no mangue e, eventualmente, pousar na roça, na casa daqueles por quem se está ligado por laços de parentesco.

Um terceiro modo de ser extrativista é a reterritorialização da segunda, quando a moradia na cidade torna-se permanente. É o caso da maior parte dos moradores da Avenida, área periférica da cidade, de ocupação antiga, que veio da roça. Muitos deles acessam o manguezal de forma permanente e vivem integralmente do extrativismo, apesar de levar uma vida que o IBGE classificaria como urbana, pelo fato de ter sua moradia na cidade.

A quarta modalidade de relação com o manguezal é uma espécie de contrapartida ou efeito recíproco da segunda e da terceira: nas conjunturas em que o manguezal está batido, isto é, com poucos recursos, os moradores da roça podem alojar-se por uma temporada na casa de parentes na cidade em busca de outras fontes de renda. A casa na cidade funciona, portanto, como um pouso para pessoas de uma mesma família, que saem dos sítios e dirigemse à cidade para trabalhar em biscates ou vender os mariscos coletados. No caso estudado, a casa de Jane e Genilson serve como pouso para os parentes que ainda possuem casas na roça. Evidentemente, nem na cidade, nem na roça a unidade de moradia coincide com o núcleo familiar: é muito comum encontrar irmãos, tios, primos, sobrinhos, cunhados e agregados pousando numa mesma casa na cidade ou na roça ou, inversamente, pessoas de uma mesma família pousando em diferentes casas. Por isso, a contagem da população extrativista com base no critério "unidade familiar", supondo uma família nuclear por unidade habitacional num dado território, não faz jus à complexidade dos arranjos familiares passíveis de coabitar a mesma casa, nem aos múltiplos desdobramentos habitacionais de uma mesma família. Uma casa comporta muitas famílias e uma mesma família distribui-se por muitas casas.

Uma quinta modalidade de relação com o manguezal pode ser concebida como uma desterritorialização das quatro primeiras: expedições para áreas de difícil acesso em que há fartura para se fazer o giro. Nesses locais, os extrativistas montam ranchos - habitações temporárias erguidas com lonas e recursos disponíveis no entorno - e aí pernoitam de três 
a quatro dias, por vezes durante uma semana. No tempo do caranguejo farto, Genilson conseguia tirar até 600 reais por semana. Mais recentemente, porém, quando tinham muita sorte, ele e sua esposa conseguiam tirar 150 reais por semana. Apesar de viverem próximos ao giro, Genilson e seus familiares precisavam muitas vezes recorrer a essas expedições mais trabalhosas manguezal adentro para conseguir encontrar o caranguejo: "é porque aqui não tem mais. Então nós vamos lá pra dentro porque lá o mangue é grande. Mas pouca gente pode ir com a gente, é pena que não dá pra levar todo mundo”. Genilson paga 15 reais para um dono de barco levá-los até uma região do rio do Largo onde o manguezal ainda está bastante profícuo: "Nós vamos lá porque lá tem mangue à vontade para trabalhar, cada um espalha para o seu lado e tem mangue à vontade". A viagem dura duas horas. Chegando lá, armam um acampamento, o rancho: nas barracas, dormem de 5 a 6 pessoas sobre tapetes, cobertas por um telhado feito com gravetos, palha e lona. As excursões duram tempo suficiente para coletar uma boa quantidade de caranguejo, sururu, ameixa e ostra, que poderá ser vendida na feira em épocas próximas a feriados e datas festivas. Ranchos similares são montados quando aparecem pessoas de fora em busca de frutas, ervas e sementes da região. Recentemente, Genilson fez um rancho para catar a folha e a semente da aroeira, que estavam muito bem cotadas entre os atravessadores.

No caso estudado, tomaram parte na expedição Pedrinho (irmão de Genilson, que vive na roça e corresponderia ao primeiro modo de ser extrativista descrito), Jane e Genilson, que possuem casa na cidade, mas vivem do mangue e esperam voltar para a roça (o segundo modo de ser extrativista); Piaba, que vive permanentemente na cidade e acessa o manguezal eventualmente (correspondente ao terceiro modo de ser extrativista) e Lena, cunhada de Genilson, que está na cidade trabalhando como empregada doméstica e morando temporariamente com os cunhados, apesar de ter sua casa na Tapera (quarto modo de ser extrativista).

As outras duas modalidades de relação com o manguezal são a das crianças e do pescador de alto-mar. O manguezal dos pescadores de alto-mar carrega as marcas da perda e da descaracterização do seu modo de vida, em função da recente e proeminente queda dos outrora fartos estoques pesqueiros da região. Em minha primeira ida a campo, no já longínquo ano de 2002, realizei algumas entrevistas com pescadores da cidade sobre os impactos ambientais das obras de dragagem do porto particular da empresa Aracruz Celulose, então recém-instalado na cidade. Na ocasião, os pescadores estavam muito apreensivos com as mudanças no clima da região - segundo eles, causadas pelas plantações de eucalipto - e a 
resultante dificuldade de se prever as condições de pesca. Outro temor à época era de que o descarte de sedimentos revolvidos do fundo do mar pela dragagem que viabiliza a passagem da balsa de eucaliptos afetasse o principal pesqueiro de camarão da região, próximo à Barra Velha, distrito de Nova Viçosa.

Couro de Lixa, pescador veterano, esperava, em 2002, que a dragagem não fosse atingir o pesqueiro de camarão, mas, caso isso acontecesse, argumentava que havia ainda um último recurso, entendido pelos pescadores como uma atividade menos nobre, porém muitas vezes necessária: a coleta de caranguejo no mangue. Disse-me na época Couro de Lixa: “caranguejo, esse aí nunca faltou". No entanto, em 2003, aconteceu o que pescadores e marisqueiros locais mais temiam: o crustáceo, visto como o último recurso pelos pescadores de alto-mar, desapareceu por completo dos manguezais caravelenses. Nisso pode ser entendida uma sexta modalidade de ser extrativista: o manguezal seria uma espécie de "amortecedor social" que impede, em conjunturas econômicas particularmente desfavoráveis, que os moradores da cidade resvalem na miséria, garantindo padrões mínimos de segurança alimentar.

Por fim, conheçamos o manguezal das crianças moradoras da parte periférica da cidade, a Avenida. O terreno contíguo à sede do Movimento Cultural Afro-indígena é um sítio, cujos limites tangem tanto a Avenida quanto o mangue. As crianças têm entre 5 e 14 anos e costumam brincar juntas nas ruas da Avenida, na sede do Movimento Cultural ou nos pastos, matas e manguezais que compõem o sítio, situado numa área que é, a um só tempo, rural e urbana. A notícia de que uma fazenda de camarão poderia vir a poluir o rio dos Macacos preocupou-as e gerou perguntas e inquietações. "Você não sabia que esses riachos que descem até o sítio vêm do rio dos Macacos [local previsto para a localização da fazenda]?”, indagou-me uma delas. "Eu já segui o caminho desse riacho aí escondido da minha mãe e fui sair lá no Bairro Novo, que é onde passa o rio dos Macacos”, confirmou outra.

O conhecimento empírico das crianças sobre as conexões surpreendentes entre os muitos rios, córregos, nascentes e braços de mar da região levou-as à conclusão imediata de que a poluição em um ponto acima de um rio distante poderá distribuir-se por seus afluentes próximos, uma vez que "o rio corre e a sujeira também”. No mangue, Rui costuma capturar o guaiamum, crustáceo que está habituado a comer, presentear a seus pais e avós ou vender, ganhando algum dinheiro, com que ajuda a família a pagar o gás e, com o troco, compra doces para si e seus irmãos. Foi o tio que lhe ensinou a fazer armadilhas de lata - as ratoeiras - para pegar o guaiamum no mangue seco. Rui passa manhãs inteiras construindo armadilhas 
e aventurando-se no mangue atrás dos crustáceos desejados. Isso é motivo de orgulho para a mãe, que costuma contar alegremente quantos guaiamuns o filho captura por dia e convidar as amigas para comer a iguaria.

As crianças sabem que não podem ir muito longe nem demorar muito, porque, embora tenham uma grande margem de independência e liberdade - especialmente se comparadas às crianças da cidade grande -, os pais podem a qualquer momento querer saber onde elas estão. Mas vez por outra gostam de escapar, aventurar-se, arriscar-se no desconhecido. O manguezal é um dos lugares escolhidos para essas fugas, por ser uma área aberta, sem dono, como elas dizem, e todavia próxima. Elas sabem que o fundo do sítio é formado por alagados, riachos e manguezais, terras habitadas por animais, os quais aprendem desde cedo a identificar e se relacionar, como caranguejos, guaiamuns, garças, patos, tatus, mas também jacarés, cobras e gatos-do-mato. O manguezal é fonte de brincadeiras, conhecimento, sonhos, medos, alimentos, fantasmas, presentes e fugas que permite às crianças ficar a sós consigo mesmas e refletir sobre si e sobre o mundo. Nesse espaço lúdico, a produção não foi sobrecodificada pelo trabalho, tomado aqui no sentido dado por Clastres (1978), para quem o conceito de trabalho sempre supõe sobretrabalho e alienação. O manguezal das crianças é, portanto, fonte de recursos que se extraem brincando. É uma produção desejante inseparável da alegria, do prazer de correr riscos e de novas descobertas. Manguezal como espaço de exercício da liberdade e da autonomia, o sétimo modo, o modo-criança de ser extrativista.

\section{Considerações finais}

Em resumo: há (1) os marisqueiros que possuem casa na roça e tiram seu giro do mangue; (2) por desterritorialização do primeiro modo, há aqueles que possuem casa temporária na cidade e pouso na roça; (3) por reterritorialização do segundo modo, há aqueles que possuem casa definitiva na cidade e que tiram seu giro do mangue; (4) há marisqueiros que possuem casas na roça e pousam na casa de parentes na cidade; (5) há, ainda, aqueles que constroem ranchos improvisados na mata para acessar o mangue; e, finalmente, há (6) os pescadores de alto-mar que acessam o manguezal como último recurso e (7) as crianças, para quem o manguezal é o primeiro recurso.

Uma possível abordagem sobre o tema seria a de afirmar que os diferentes sujeitos aqui isolados teriam diferentes representações sociais e políticas referentes a um mesmo 
território, no sentido de determinada porção do ambiente biofísico do município. O território, na acepção comumente acionada por nós, antropólogos, nasceria de uma espécie de conversão do ambiente natural em ambiente social, que se processaria por meio do trabalho da história e da cultura. No entanto, parece-me que tal concepção estratigráfica de território - base natural sobre a qual sobrepõem-se representações sociais -, em vez de conduzir nossas análises adiante, pode ser justamente o fator que as impede de avançar.

Tim Ingold (2000) designou esse modo de se pensar o território como oriunda de um relativismo perceptivo, que repousa precisamente na ideia de que haveria uma base natural dada sobre a qual são construídas diferentes representações que variariam segundo os agentes sociais em questão. Um mesmo objeto é percebido ou apreendido de diferentes formas, segundo os pontos de vista dos diferentes sujeitos, que o constroem de modos distintos. Assim, teríamos representações sobre um mesmo objeto, dado a priori, que mudariam de acordo com o sujeito em questão ou segundo sua posição num determinado campo de disputas. O estudo do meio ambiente como um dado caberia ao biólogo e o estudo das representações em disputa sobre ele seria tarefa do cientista social, numa operação que recorta o objeto em partes, cujo escrutínio remete a competências distintas, favorecendo assim uma divisão social do trabalho científico.

A proposta aqui delineada é singela: se olharmos para o meio ambiente como algo que não está dado previamente, o que sobra? Os percursos heterogêneos e múltiplos traçados pelos moradores, que nos fornecem as distintas modalidades da relação das populações extrativistas com o manguezal. Assim, assumindo o ponto de vista de pescadores, marisqueiros e crianças, propusemos entender o território como algo que não é dado a priori, apresentando um relato etnográfico que enfatiza as conexões entre acontecimentos políticos, relações de parentesco, vizinhança, cooperação e amizade e movimentos e percursos desenhados pelos diferentes grupos que produzem certo manguezal. Enfatizamos que é o movimento desses grupos que os distinguem qualitativamente e não o pertencimento a um dado território. Seguindo de perto os percursos heterogêneos e múltiplos por eles traçados, foi possível identificar sete modos de ser extrativista, mas certamente há muitos outros que não pudemos enxergar ou mapear.

Os exemplos etnográficos aqui apresentados nos remetem a uma proliferação de modos-de-ser-extrativista que muitas vezes não são levados em conta nas abordagens tradicionais que entendem a identidade desses actantes como una e indiferenciada e sua fixação a um dado território como natural. Trata-se de uma forma-Estado de pensamento 
(Deleuze e Guattari, 1980: 466), que prevê um território dado, delimitado por fronteiras, englobando um grupo ou um povo dotado de uma identidade determinada. O caso aqui apresentado nos revela que, ao "suspendermos" o território como pressuposto da análise, liberamos os fluxos presentes nos caminhos traçados pelas práticas ecológicas e históricas das populações extrativistas. Adotando sua perspectiva, não há coincidência total entre uma suposta identidade extrativista, seu lugar de moradia, o acesso aos recursos e o território em que se estabeleceu uma Reserva Extrativista. Por fixar-se previamente ao território, corre-se o risco, por exemplo, de desconsiderar como dotados da "identidade" de extrativista os grupos urbanos que vivem do extrativismo. É assim que a etnografia e as pesquisas de longa duração podem contribuir à elaboração de uma cartografia não fundada no primado naturalizante do território biofísico, liberando outras possibilidades de análise que compreendam os acontecimentos, os fluxos e as intermitências da vida social enquanto elementos fundamentais para tornar os processos estudados mais inteligíveis.

Busquei, com este trabalho, fazer o exercício de olhar para os grupos extrativistas extraindo deles seu território. Essa operação de minoração (Deleuze, 1975) levou-nos a enxergar outras dimensões negligenciadas pelas abordagens que entendem como natural a fixação dos extrativistas a um território dado. O efeito paradoxal de tal procedimento é o de que, ao subtrair o território da análise, este finalmente se amplia e, ao olhar para os muitos caminhos traçados pelos grupos extrativistas, estes também se multiplicam.

\section{Notas}

${ }^{1}$ Professora Adjunta do Instituto de Pesquisa e Planejamento Urbano e Regional da UfRJ e pesquisadora do CNPq.

${ }^{2} \mathrm{O}$ trabalho de campo desenvolveu-se durante 24 meses, distribuídos nos anos de 2004, 2005, 2006, 2009, 2013 e 2014.

${ }^{3}$ Categorias nativas estão grifadas em itálico ao longo do texto.

${ }^{4}$ Para uma discussão aprofundada sobre a noção de afro-indígena neste contexto etnográfico, ver Goldman (2014) e Mello (2014).

${ }^{5} \mathrm{O}$ exercício de minoração é uma operação, um tratamento ao material, proposto por Gilles Deleuze (2010), inspirado pela obra do dramaturgo italiano Carmelo Bene, cujas experimentações "amputavam" os protagonistas de peças conhecidas, de modo a permitir o crescimento de personagens que seriam secundárias ou de virtualidades não desenvolvidas na peça original. O efeito desta operação de subtração não seria negativo; antes, ela permitiria e desencadearia processos positivos. Nas palavras do filósofo: "Mas o que sobra? Sobra tudo, mas sob uma nova luz, com novos sons, novos gestos" (Deleuze, 2010: 
42). A presente análise inspira-se na transposição que Goldman (2014) e Barbosa (2004) fazem desse procedimento para a análise antropológica.

${ }^{6}$ Calcula-se que cerca de 65\% da População Economicamente Ativa (PEA) do município viva da pesca e da mariscagem (cf. Moura, 2005: 15).

${ }^{7}$ Os efeitos sociais e subjetivos da extinção da ferrovia Bahia-Minas foram imortalizados na canção de Milton Nascimento e Fernando Brandt Ponta de Areia.

${ }^{8}$ O Parque Nacional Marinho dos Abrolhos é uma Unidade de Conservação de Proteção Integral criada em 1983. Trata-se de uma região considerada por especialistas como de concentração da maior biodiversidade marinha do Atlântico Sul (Dutra et al, 2005).

${ }^{9}$ As empresas de celulose Aracruz (atualmente Fibria) e Bahia Sul são proprietárias de 43\% das terras do município de Caravelas (Koopmans, 1995: 74).

${ }^{10}$ As fazendas de camarão são um conjunto de grandes tanques, construídos sobre manguezais, em que são introduzidos larvas de camarão, grandes quantidades de ração, hormônios para a engorda e antibióticos necessários para impedir o alastramento de epidemias. Esses produtos são vendidos em pacotes tecnológicos por empresas de grande porte dos ramos químico, farmacêutico e alimentício e possibilitam até três ciclos produtivos por ano.

${ }^{11}$ Governos e órgãos multilaterais investiram maciçamente na agroindústria do camarão durante as décadas de 1980 e 1990 e sua expansão geográfica deu-se a partir do sudeste asiático para a costa do Pacífico da América do Sul, da América Central e do Nordeste brasileiro. No Brasil, a criação do Ministério da Pesca e Aquicultura e investimentos públicos do bndes, do Banco do Nordeste e da Sudene aumentaram exponencialmente a produtividade da carcinicultura voltada para a exportação.

${ }^{12}$ Analisada em detalhe em Mello (2015).

${ }^{13} \mathrm{O}$ manguezal das crianças do movimento cultural, que em muitos sentidos se aproxima daquele dos pescadores e marisqueiros, será apresentado na última seção deste artigo.

${ }^{14}$ Esclareço que as fontes empíricas aqui acionadas diferem substancialmente de acordo com o actante em questão. Isso porque a pesquisa de campo realizou-se com muito mais proximidade dos chamados grupos extrativistas do que dos pesquisadores ligados às ONGs ambientalistas e dos empresários. As reflexões sobre pesquisadores e empresários baseiam-se em fontes secundárias, como publicações e relatórios disponibilizados publicamente.

${ }^{15}$ Cabe modular que, evidentemente, há outros tipos de "homens de esquerda". A partir de 2007, o primeiro ato administrativo do secretário de recursos hídricos do recém-empossado governo Jacques Wagner foi a suspensão da outorga de água para a fazenda de camarão que se instalaria em Caravelas, inviabilizando a atividade.

${ }^{16}$ Um processo que Harvey (2011) denominou, a partir do conceito de acumulação primitiva de Marx e das análises de Rosa Luxemburgo, de "acumulação por despossessão".

${ }^{17} \mathrm{O}$ material empírico que dá sustentação a este item é o Parecer Independente sobre o EIA-RIMA da fazenda de camarão, elaborado por Moura et al. (2005), documento oriundo de uma associação entre pesquisadores de diferentes áreas e universidades, que reúne de forma ao mesmo tempo densa e sintética o acúmulo científico sobre a importância biológica e socioeconômica dos manguezais da região.

${ }^{18}$ Trata-se de prática científica distinta da prática do cientista experimental fechado em seu laboratório, pois, enquanto pesquisadores de campo, precisam lidar com um mundo em sua rugosidade e heterogeneidade próprias, um mundo recalcitrante (Latour, 2004), que resiste às tentativas de purificação 
e generalização próprias às ciências experimentais strictu sensu.

${ }^{19} \mathrm{Na}$ bibliografia especializada, há uma série de publicações sobre a destruição dos ecossistemas e as violações dos direitos humanos praticadas pela agroindústria do camarão em cativeiro (Shanahan et al., 2003; Fahn, 2003; Warne, 2011).

${ }^{20}$ Cf. Acselrad (2010).

${ }^{21}$ Cf. Batista e Tupinambá (2004).

${ }^{22}$ Relatórios sobre as violações de direitos no processo de expansão da carcinicultura nos estados do Ceará (Leroy e Silvestre, 2004) e da Bahia (Rede MangueMar, 2007; Ettern e Fase, 2011) descrevem como as fazendas de camarão vieram acompanhadas de ameaças de morte, perseguições, espancamentos, tortura e assassinatos. O caso mais emblemático do quadro de violência política que se instaurou nestes municípios foi o do pescador Paulo Marinho de Almeida, de Salinas da Margarida (BA), então com 33 anos e pai de quatro filhos, sequestrado, torturado e executado em 2005 a mando de donos de fazenda de camarão (Viana, 2007: 104).

${ }^{23}$ Para uma discussão sobre grandes projetos e violência em comunidades pesqueiras, ver Rougemont (2015).

${ }^{24}$ Estes blocos - embora independentes - são apoiados e articulados pelo Movimento Cultural Arte Manha. Sobre o devir-afroindígena, ver Mello (2014). Sobre política e arte junto ao grupo, ver Mello (2010).

${ }^{25}$ Os conceitos de desterritorialização e reterritorialização aqui apresentados são emprestados de Deleuze e Guattari (1980) na medida em que exprimem um esforço de criação conceitual que busca dar conta da ideia de que "não há território sem um vetor de saída do território e não há saída do território sem, ao mesmo tempo, um esforço para se reterritorializar em outra coisa” (Deleuze, 1988).

${ }^{26}$ Importante notar que, embora o laudo socioeconômico da população da Resex restrinja-se ao perfil dos moradores permanentes do território delimitado pelo perímetro da Unidade de Conservação, há uma indicação clara de que os grupos sociais que acessam os recursos do manguezal não se restringem a estes: "A área proposta para a criação da nova Unidade de Conservação tem uma extensão de 23.710 hectares onde residem aproximadamente 1.372 pessoas, em mais de 300 famílias - não considerando as familias urbanas, descendentes da comunidade local, e que também dependem desse ecossistema" (MMA, 2005: 7, grifo nosso).

\section{Referências bibliográficas}

\section{Acselrad, Henri}

2010 “Ambientalização das lutas sociais - o caso do movimento por justiça ambiental". Estudos Avançados, v. 24, n. 68: 103-119.

BAHIA PESCA

2003 Macrodiagnóstico do potencial da Babia para carcinicultura marinha. Salvador. CD-ROM. 
BArbosa, Gustavo

2004 "A Socialidade contra o Estado: a antropologia de Pierre Clastres". Revista de Antropologia, São Paulo, v. 47, n. 2: 529-576.

Batista, Pedro Ivo e Tupinambé, Soraya Vanini

2004 "A carcinicultura no Brasil: o agronegócio do camarão". Cadernos sobre Comércio e Meio Ambiente, Rio de Janeiro, n. 3: 63-82.

Browder, John O. e Godfrey, Brian J.

1997 Rainforest Cities: Urbanization, Development, and Globalization of the Brazilian Amazon. Nova York, Columbia University Press.

Castro, Josué

1967 Homens e caranguejos. São Paulo, Brasiliense.

Clastres, Pierre

1978 A Sociedade contra o Estado: pesquisas de Antropologia Política. Rio de Janeiro, Francisco Alves.

Coelho-Júnior, Clemente e ShefFer-Novelli, Yara

2000 "Considerações teóricas e práticas sobre o impacto da carcinicultura nos ecossistemas costeiros brasileiros, com ênfase no ecossistema manguezal". Mangrove 2000 - Sustentabilidade de Estuários e Manguezais: Desafios e Perspectivas. Recife, CD-ROM.

Deleuze, Gilles e Guattari, Félix

1980 Capitalisme et schirophrénie 2: Mille plateaux. Paris, Minuit.

Deleuze, Gilles

1988 “A comme Animal, L’Abécédaire de Gilles Deleuze”. França, direção e produção de Pierre-André Boutang, 480 min.

2010 Sobre teatro: um manifesto de menos. Rio de Janeiro, Zahar.

DutRA, Guilherme, et al.

2005 “A Rapid Marine Biodiversity Assessment of the Abrolhos Bank, Bahia, Brazil”. RAP Bulletin of Biological Assessment, Conservation International, Washington DC, 38. 
ETTERN-IPPUR; Fase

2011 Projeto Avaliação de Equidade Ambiental como instrumento de democratização dos procedimentos de avaliação de impacto de projetos de desenvolvimento. Rio de Janeiro, FASE, 173p.

FAHN, James

2003 A Land on Fire: The Environmental Consequences of the Southeast Asian Boom. Colorado, Westview Press.

Foucault, Michel

1994 Dits et écrits. Vol. 4. Paris, Gallimard.

\section{GEERTZ, Clifford}

1989 "O impacto do conceito de cultura sobre o conceito de homem". In

A interpretação das culturas. Rio de Janeiro, LTC, pp. 45-66.

Goldman, Marcio

2014 “A relação afro-indígena”. Cadernos de Campo, v. 23, n. 23: 213-222.

\section{GT CARCINICULTURA}

2005 "Relatório do Grupo de Trabalho destinado a realizar diagnóstico sobre os impactos da carcinicultura (cultura de crustáceos em viveiros) no meio ambiente, nas regiões Norte e Nordeste". Comissão de Meio Ambiente e Desenvolvimento Sustentável da Câmara Federal. Brasília, 102p.

GuimarãES, Iveraldo

2005 "Homens-caranguejo: os filhos da lama". Revista da Associação Brasileira de Criadores de Camarão, ano 7, n. 3: 19-20.

HARVEY, David

2011 O novo imperialismo. São Paulo, Loyola.

INGOLD, Tim

2000 The Perception of the Environment: Essays on Livelihood, Dwelling and Skill. Londres e Nova York, Routledge. 
KoOpmans, José

1995 Além do eucalipto: o papel do Extremo Sul. Teixeira de Freitas (BA), Centro de Defesa dos Direitos Humanos.

Latour, Bruno

1994 Jamais fomos modernos: ensaio de Antropologia Simétrica. Rio de Janeiro, Editora 34.

2004 "How to Talk about the Body". Body and Society, v. 10, n. 2-3: 205-229.

2005 Reassembling the Social: An Introduction to Actor-Network Theory. Oxford, Oxford University Press.

Leroy, Jean-Pierre e Silvestre, D. R.

2004 "Populações litorâneas ameaçadas: carcinicultura, pesca industrial, turismo, empreendimentos públicos e poluição”. Relatório da Missão a Pernambuco, Ceará e Rio Grande do Norte, Relatoria Nacional para o Direito Humano ao Meio Ambiente, Projeto Relatores Nacionais em DhESC. Curitiba, 58p..

LÉvi-STrauss, Claude

1980 Raça e história. Coleção Os Pensadores. São Paulo, Abril Cultural.

Mello, Cecília Campello do A.

2014 "Devir-afroindígena: 'então vamos fazer o que a gente é". Cadernos de Campo, v. 23, n. 23: 223-239.

2015 "Do meio do medo nasce a coragem - o encontro entre pescadores e marisqueiras de Caravelas (BA) e do Ceará e os múltiplos sentidos da política”. Revista Brasileira de Estudos Urbanos e Regionais, v. 17, n. 3: 134-149.

Moura, R. L. et al.

2005 Parecer independente e questionamentos sobre o ELA-RIMA do projeto de carcinicultura da Cooperativa dos Criadores de Camarão do Extremo Sul da Babia (Coopex). Caravelas (BA). mimeo.

Mumby, P. J. et al.

2004 "Mangroves enhance the biomass of coral reef fish communities in the Caribbean". Nature, 427: 533-536. 
Ostrom, Elinor

1990 Governing the Commons: The Evolution of Institutions for Collective Action. Nova York, Cambridge University Press.

Ministério do Meio Ambiente (mma)/Núcleo Assessor de planejamento da mata ATLÂNTICA (NAPMA)

2005 Laudo Socioeconômico para a criação de novas Unidades de Conservação: Região da Ilha do Cassurubá. Relatório da Equipe Técnico-Científica. Projeto Mata Atlântica (BA). mimeo.

\section{Rede Manguemar}

2007 Mapeamento dos conflitos socioambientais relativos à carcinicultura no estado da Babia. Salvador (BA), CASA/Overbrook Foundation.

Rougemont, Laura

2015 Venta forte na baía de Guanabara: a resistência dos(as) pescadores(as) da Associação Homens e Mulheres do Mar (Ahomar) frente à instalação do Comperj (Complexo Petroquímico do Rio de Janeiro). Rio de Janeiro, dissertação, UFRJ.

SCHMIDT, Anders

2006 Estudo da dinâmica populacional do caranguejo-uçá, Ucides cordatus cordatus, e dos efeitos de uma mortalidade em massa desta espécie em manguezais do sul da Babia. São Paulo, tese, uSP.

SHANAHAN, Mark et al.

2003 Smash \& Grab: Conflict, Corruption and Human Rights Abuses in the Shrimp Farming Industry. Londres, Environmental Justice Foundation.

VIANA, Natália

2007 Plantados no chão: assassinatos politicos no Brasil hoje. São Paulo, Conrad.

WARNE, Kennedy

2011 Let Them Eat Shrimp: The Tragic Disappearance of the Rainforests of the Sea. Washington/Covelo/London, Island Press/Shearwater Books. 


\title{
The entrepreneur, the NGO, the crab collectors, the child: a case study on the variation of meanings of a mangrove in dispute
}

\begin{abstract}
This article intends to present some theoretical and methodological inflections based on an ethnographic study of a mangrove area occupied by extractive groups in Northeast Brazil. It intends to present how the different actants in dispute - namely, entrepreneurs, researchers associated with environmental NGOs, the shellfish and crab collectors and the children of a cultural movement - define and use what they designate, each in its own way, shrimp farm, mangrove ecosystem or simply mangrove. From a long-term field research, this paper proposes the analytical exercise of approaching native routes and displacements, making it possible to apprehend the multiple ways of being extractive and indicating, as a result, the need for a complexification of the concept of group or extractive population.
\end{abstract}

KEYWORDS: Ethnography, Extractive Reserves, Environmental Conflict, Territory, Cassurubá, Bahia.

Recebido em fevereiro de 2015. Aceito em dezembro de 2015. 